Research Paper

\title{
Marketing Culture and Its Role In Enhancing Competitive Advantage/ A Survey Study In Nowruz, The Internet Service Provider in Duhok
}

Journal of

\section{TANMIYAT AL- RAFIDAIN}

\section{(TANRA)}

A scientific, quarterly, international, open access, and peer-reviewed journal

Vol. 40, No. 132

December 2021

(C) University of Mosul | College of Administration and Economics, Mosul, Iraq.

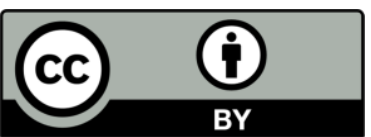

TANRA retains the copyright of published articles, which is released under a "Creative Commons Attribution License for CC-BY-4.0" enabling the unrestricted use, distribution, and reproduction of an article in any medium, provided that the original work is properly cited.

Citation: Khalid, Dalal A., Munther K. Yaqoob, (2021). "Marketing culture and its role in enhancing competitive advantage/ A survey study in Nowruz, the Internet service provider in Duhok". TANMIYAT AL-RAFIDAIN,40 (132), 287-303, https://doi.org/ 10.33899/tanra.2021.170364

P-ISSN: 1609-591X e-ISSN: 2664-276X tanmiyat.mosuljournals.com

\section{Dalal A. Khalid ${ }^{1}$ ! Munther K. Yaqoob ${ }^{2}$ \\ ${ }^{1 \& 2}$ Administration \& Economics College, University of Al Mosul}

Corresponding author: Dalal A. Khalid, Administration \& Economics Colleg, University of Al Mosul

Dalal.bap137@student.uomosul.edu.iq

DOI: https://doi.org/ 10.33899/tanra.2021.170364

Article History: Received: 5/6/2021; Revised: 15/6/2021; Accepted: 22/6/2021; Published: 1/12/2021.

\section{Abstract}

The current research aims to identify the dimensions of marketing culture represented by (service quality, diversity, rationality, internal relations, and innovation), and its role in enhancing competitive advantage in companies in general, especially service ones, by addressing the research problem represented by the following questions: Are the dimensions of marketing culture available in the researched company? What are the relationships and the impact relationship between marketing culture and competitive advantage?, and research hypotheses were formulated, including There is a significant correlation between marketing culture and competitive advantage at the macro and micro level at the level of significance 0.05, and there is a significant effect of marketing culture on the competitive advantage at the level of morale 0.05 The descriptive-analytical method was used, as a sample of (70) employees working in the Nowruz company, which provides Internet services in Dohuk governorate, was selected. A questionnaire was designed to collect data, and its paragraphs were analyzed to test the research hypotheses using the SPSS Ver. 24, and the research reached some conclusions, the most important of which were: that the marketing culture is of great importance in companies, especially service ones, being in direct contact with customers, and the research reached several recommendations, the most important of which were: the need to pay attention to marketing culture as it reflects the identity of the company and its position among competing companies In the market.

\section{Keywords:}

marketing culture, competitive advantage. 


\section{الثقافة التسويقية ودورها في تعزيز الميزة التنافسية/ دراسة استطلاعية في شركة نوروز المزودة لخدمات الانترنت في مدينة دهو} إ\& كلية الإدارة والاقتصاد، قسم إدارة التسويق، جامعة الموصل، المؤلف المراسل:دلال عكيد خالد ، كلية الإدارة والاقتصاد، جامعة الموصل، العراق Dalal.bap137@student.uomosul.edu.iq

DOI: https://doi.org/ 10.33899/tanra.2021.170364

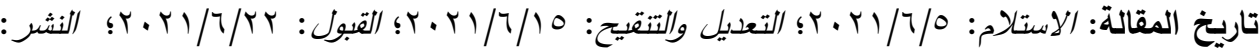
$\cdot r \cdot r \mid / T / 1$

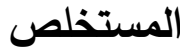

يهدف البحث الحالي إلى التعرف على أبعاد الثقافة التسويقية والمتمثلة باجودة الخدمة، والتنوع، والعقلانية، والعلاقات الداخلية، والابتكار)، ودورها في تعزيز الديزة التنافسية في الشركات عامة لاسيها

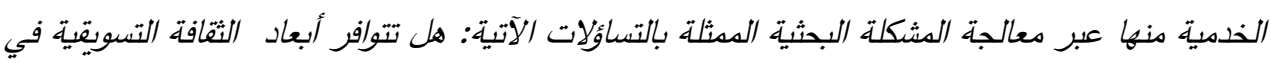

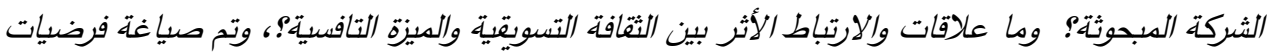
بثيه منها: هناك علاقة ارتباط ذات دلالة معنوية بين الثقافة التسويقية والميزة التنافية على الدستوى الكلي

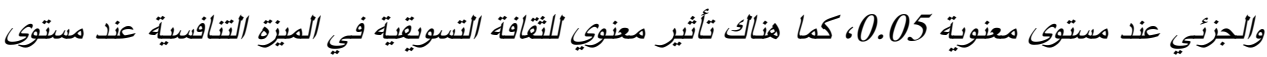

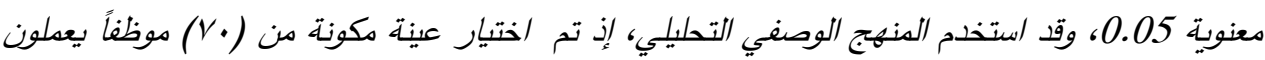
في شركة نوروز المزودة لخدمات الانترنت في محافظة دهوك، وتم تصديم استصارة استبانة لجدع البيانات، وتحليل فقراتها لاختبار فرضيات البحث باستخدام البرمجية الاحصائية 24 كونية

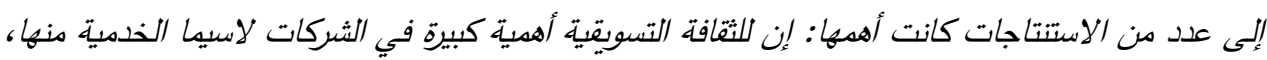

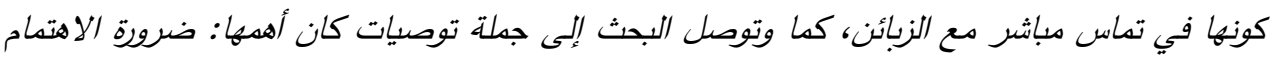
بالثقافة التسويقية كونها تعكس هوية الثركة ومكانتها بين الثركات المنافسة في السوق.

الكلمات الرئيسة الثقافة التسويقية، الميزة التنافسية.

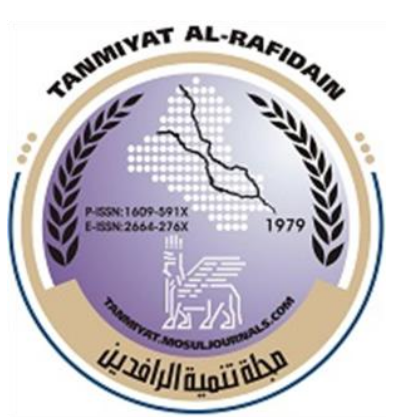

\section{هبلة}

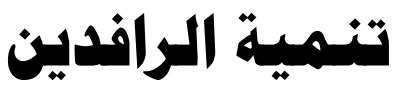

(TANRA) دولية، مفتوحة الوصول، محكمة.

$$
\begin{aligned}
& \text { المجلد (•• )، العدد (Yr I))، } \\
& \text { كانون الاول الr.r }
\end{aligned}
$$

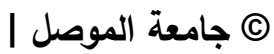
كلية الإدارة والاقتصاد، الدوصل، العرصل،

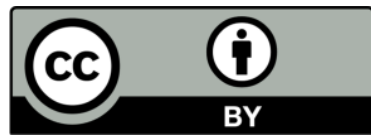

تحتفظ (TANRA) بحقوق الطبع والنشر للمقالات المنشورة، والتي يتم إصدارها بموجب ترخيص لتصن

\lrcorner (Creative Commons Attribution) (CC-BY-4.0)

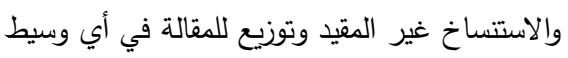
نقل، بشرط اقتباس العمل الأصلي بثكل صحيح.

الاقتباس: خالد، دلال عكيد. يعقوب، منذر

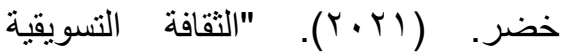
ودور ها في تعزيز الميزة التنافسية/ دراسة

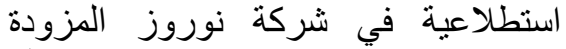

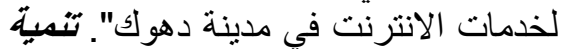

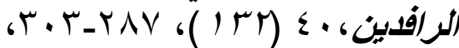
https://doi.org/ 10.33899/tanra.2021.170364

P-ISSN: 1609-591X

e-ISSN: 2664-276X

tanmiyat.mosuljournals.com 


$$
\begin{aligned}
& \text { المبحث الاول: منهجية البحث } \\
& \text { أولاً: مشكلة البحث }
\end{aligned}
$$

تعدّ الثقافة التسويقية من الموضوعات المعاصرة التي تؤثر في أنثطة المنظمات لاسيما الخدمية منها،

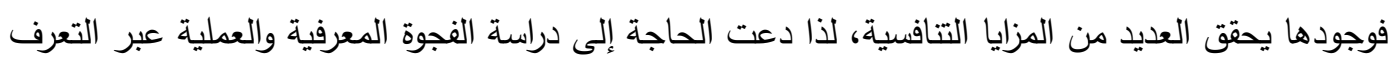
على أبعاد الثقافة التسويقية في الثركات المزودة لخدمات الانترنت، ومنها شركة نوروز المبحوثة.

$$
\text { ومن هنا يمكن طرح التساؤلات الآتية: }
$$

1. هل هناك علاقة ارتباط معنوية بين الثقافة التسويقية بأبعادها والميزة التتافسية في الشركة

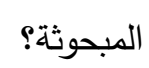

r. هل تؤثر الثقافة التسويقية في تعزيز الميزة التتافسية في الثركة المبحوثة ؟

ثانياً:أهمية البحث

تأتي أهمية البحث من أهمية موضوعات الثقافة التسويقية والميزة التتافسية، فضلاً عن أهمية المشكلة المطروحة آنفاً، إذ لم تسبق دراسة في إيجاد العلاقة الارتباطية والتأثيرية بين متغيري البحث الذية التي أولاهما

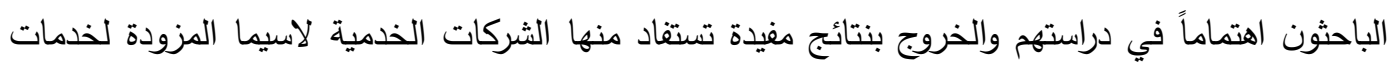

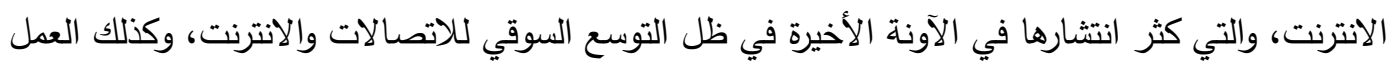

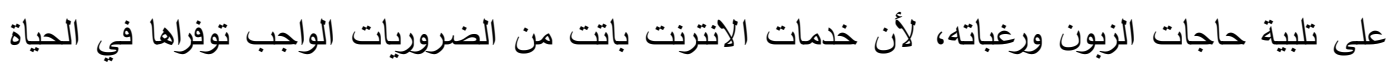
اليومية العلمية والعملية. ثالثاً:أهداف البحث من خلال ما تم عرضه من مشكلة الدراسة وأهميتها، توصل البحث إلى طرح مجموعة من الأهداف

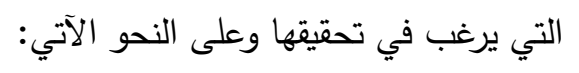

ا- التعرف على مدى إدراك الثركة المبحوثة لمفهوم الثقافة التسويقية.

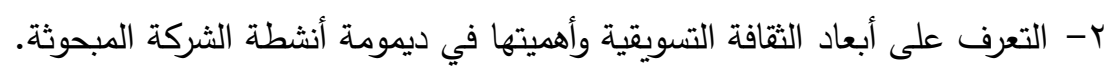
ب- التعرف على الخدمات المقدمة من الشركة المبحوثة والتي تتافس من خلالها الثركات الأخرى.

$$
\text { رابعاً: فرضيات البحث }
$$

$$
\text { تم صياغة ثلاث فرضيات رئيسة وهي: }
$$

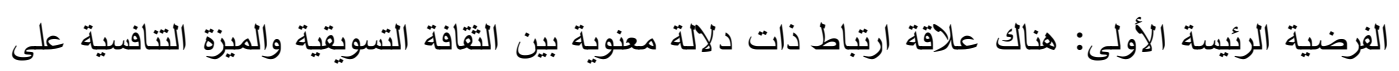

$$
\text { المستوى الكلي عند مستوى معنوية 0.05. }
$$

الفرضية الرئيسة الثانية: هناك علاقة ارتباط ذات دلالة معنوية بين كل بعد من أبعاد الثقافة التسويقية والميزة التنافسية على المستوى الجزئي عند مستوى معنوية 0.05 المئه الفرضية الرئيسة الثالثة: هناك تأثير معنوي للثقافة التسويقية في الميزة التتافسية عند مستوى معنوية 
خامساً: الأدوات الاحصائية

استخدم الباحثان مجموعة من الأدوات الاحصائية الملائمة لاختبار فرضيات البحث، وهي الإني

1- التكرارات والنسب المئوية والأوساط الحسابية والانحرافات المعيارية.

r- استخدام تحليل معامل الارتباط البسيط والمتعدد (سبيرمان)، وذلك للتعرف على طبيعة العلاقة بين المتغير المستقل والمتغير المعتمد عند مستوى معنوية 0.05 وباستخدام البرمجية الاحصائية SPSS ودئية

.VER.24

r- استخدام تحليل الانحدار البسيط لبيان تأثير المتغير المستقل في المتغير المعتمد، واحتساب قيمة t و f.

$$
\text { سادساً: مجتمع البحث وعينتها بقيمها الجدولية. }
$$

تكوّن مجتمع البحث من الشركات المقدمة لخدمة الانترنت في إقليم كوردستان العراق، أما عينة البحث المختارة فكانت شركة نوروز للاتصالات والانترنت في محافظة دهوك، وبلغ حجم العينة العشوائية المختارة

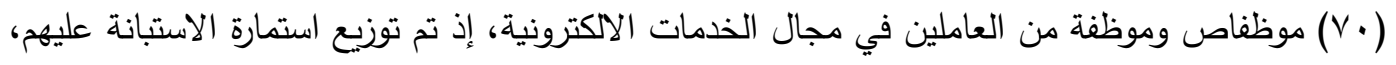

ومن ثم جمعها وتبويبها وفرزها وتحليلها والتوصل إلى النتائج المرجوة. سابعاً: حدود البحث

الحدود المكانية: تم إجراء البحث في شركة نوروز المزودة لخدمات الانترنت في محافظة دهوك.

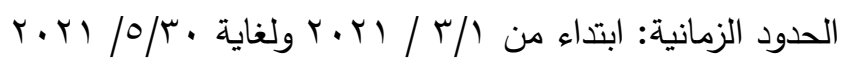

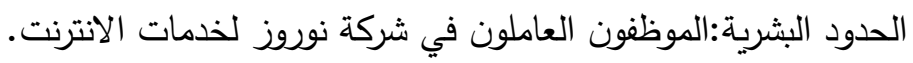

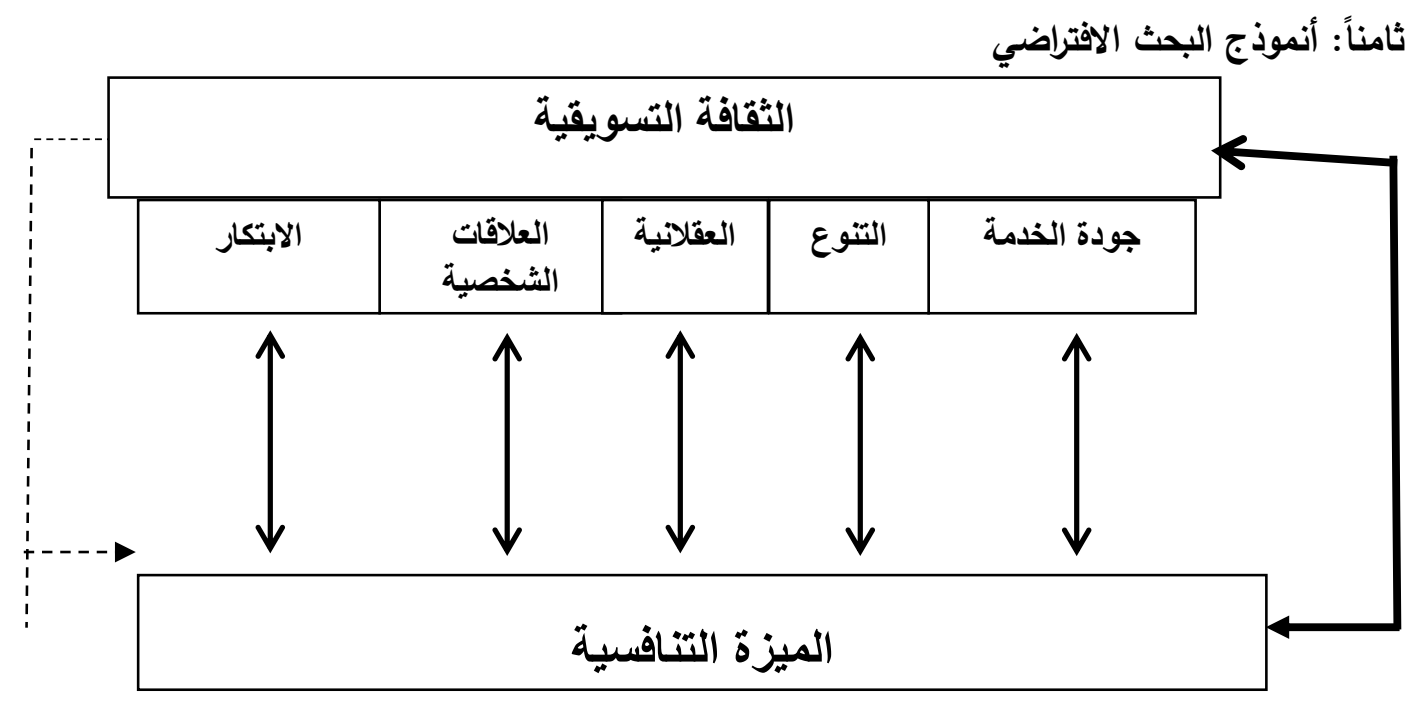

المصدر: من إعداد الباحثين بتصرف، بالاستاد إلى "العكيدي، سوسن إبراهيم رجب، (r ب ب)، "عناصر الثقافة

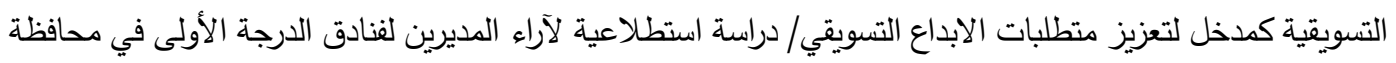
أربيل"، رسالة ماجستير غير منشورة، جامعة الموصل. 
المبحث الثاني : الإطار النظري للبحث

المحور الأول: مفهوم الثقافة التسويقية وأهميتها

اولأ: مفهوم الثقافة التسويقية معوم الائمافه

تعدّ الثقافة التسويقية واحدةً من مكونات الثقافة الكلية للمنظمة، وعنصراً من عناصر الثقافة التنظيمية

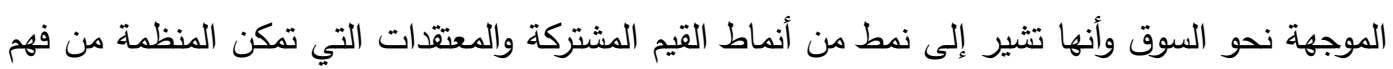
طبيعة الانشطة التسويقية،ومن ثُ تحدد قواعد السلوك المقبول من العاملين في المنظمة تجاه

الزبائن (Wbester,1995:7).

ويشتق مفهوم الثقافة التسويقية من منظورين متكاملين يتمثلان في المنظور الثقافي والمنظور السلوكي. فالمنظور الثقافي يركز على القيم التي تثجع المفاهيم المرتبطة بالتوجه بالزبائن، والتوجه بالمنافسين والتتسيق

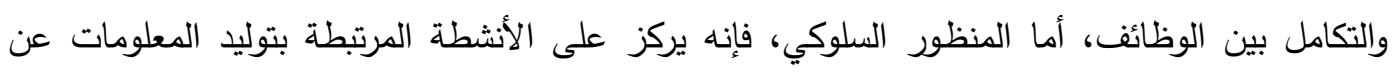
السوق، ونشرها وتبادلها، والاستجابة لها. (95anash \& khalaf,2020: 95). وقد وردت مفاهيم وتعاريف كثيرة للثقافة التسويقية وفق آراء العديد من الباحثين والكتّاب، إذ يثير

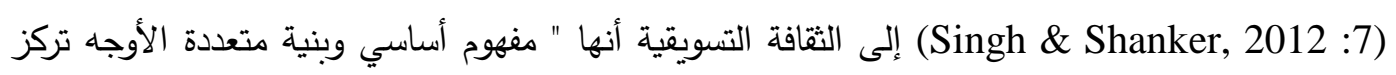
على خدمة الزبائن والأتصالات الداخلية والأبتكاروجودة الخدمة".

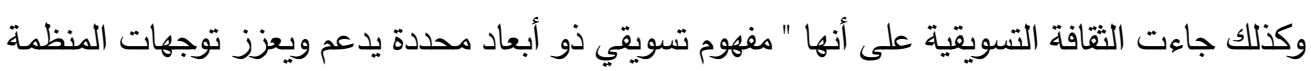

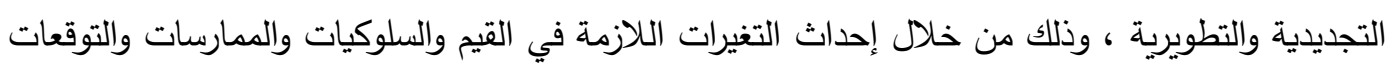
والمعتقدات ، بالاعتماد على التغيرات التي يتم إحداثها في طريقة تفكير العاملين والتي تتعكس في إبداعاتهم ولتهري بما يضمن بقاء المنظمة ونموها واستمرارها في السوق من خلال تقديم خدمات متفوقة لزبات لتبائنها"

.(Alkidi 2013:37)

أما (152: Yildirim, et al., 2017 (يرى أنها " مستوى ادراك العاملين للمشاركة بالقيم والمواقف، التي يكون التركيز الأكبر فيها منصبا على الانشطة التسويقية". ويرى(Al-Qadri 2019:75) أنها " هي في في الآلية التي تضمن تقديم عمل متقن ومستوى متكافئ مما يضمن نجاح المنظمة كما تعمل بوصفها أداة لتطوير التيري

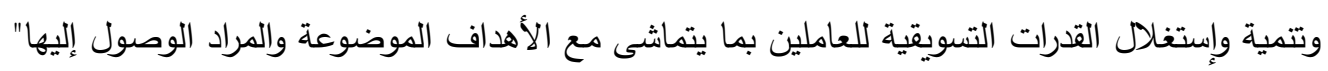

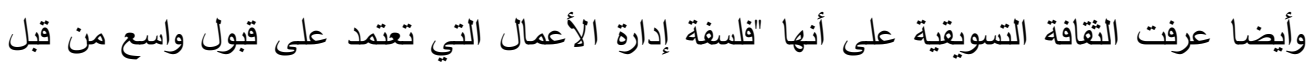
المنظمة، والتي تركز على التكامل والتنسيق لجميع وظائف التسويق التي بالمقابل تتسجم مع الوظائف الإدارية الأخرى م هذه المنظمة" (Hanash \& Khalaf, 2020:20). بذلك، فإن الثقافة التسويقية تعدّ من المفاهيم التي تدعم وتعزز مكانة المنظمة في السوق، فضلاً عن تأثيرها الواضح في تحقيق المزايا التتافسية التي من خلالها تتفوق على نظيراتها من المنظمات المنافسة الأخرى. 


\section{الثقافة التسويقية ودورها في تعزيز الميزة التنافسية .

ثانيا:أهمية الثقافة التسويقية

وضح (Salamon,2016:128) أهمية الثقافة التسويقية داخل المنظمة بالثكل الآتي :

أ- هي الأسلوب الجوهري الذي يوجه سلوكيات العاملين داخل المنظمة وخارجها.

ب- هي المفتاح الرئيس الذي يستخدمه المخطط الاستراتيجي والتتفيذي في اعتماد طريقة التنفيذ داخل

المنظمة وتوجيهـا ومراقبتها.

ت- هي السبب التي تجعل المنظمة تتكيف مع مختلف القطاعات العاملة مع المنظمة في البيئة الخارجية المحيطة بها من منافسين، وموردين، وزبائن، وأسواق متنوعة.

ث- هي الكيفية التي يتم فيها استيعاب الخصائص التي تسعى المنظمة إلى تحقيقها من أجل تقديم أداء جيد.

ج- هي الأساس الذي تبنى عليه العقلانية في التعامل مع السلوكيات والتفريق ما يجب أن نفعله ومايجب أن لا نفعله).

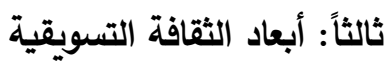

إن الثقافة التسويقية عنصر مهم لما لها من تأثير مباشر على سلوك الأفراد العاملين وأدائهر في

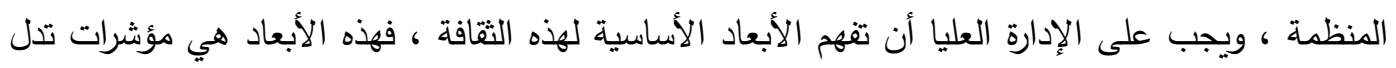

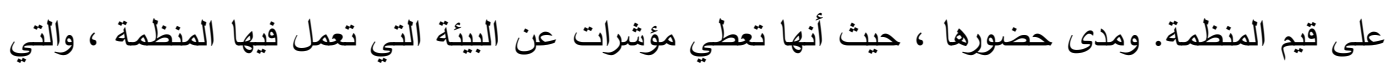
يتم من خلالها تتفيذ عمليات وأنثطة التسويق بجميع أنواعها وأهدافها ، وكذلك على الإدارة العليا فهم العوامل المحددة والمشجعة لثقافة التسويق والعمل على توظيفهم بهدف ترسيخ ثقافة تسويقية أنموذجية، فالثقافة

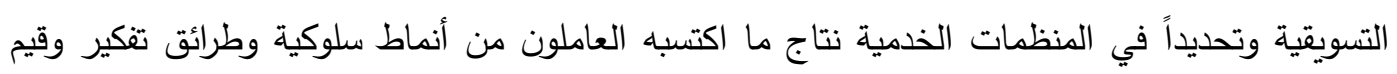

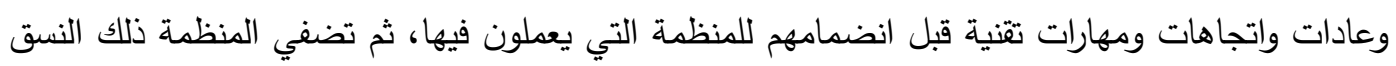
الثقافي لعامليها من خصائصها واهتماماتها وسياساتها وأهدافها وقيمها ما يحدد شخصية المنظمة ويميزها عن غيرها من المنظمات (Kotler, 2018 (K43).

واتفق عدد من الباحثين والمرتمين في الدراسات الادارية والتسويقية على وجود عدد من المؤشرات

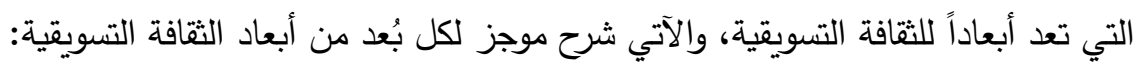
1- جودة الخدمة: (Service quality) تعدّ الجودة ذات أهمية استراتيجية وحيوية بالنسبة لكل من الزبون والمنظمة على اختلاف أنثطتها

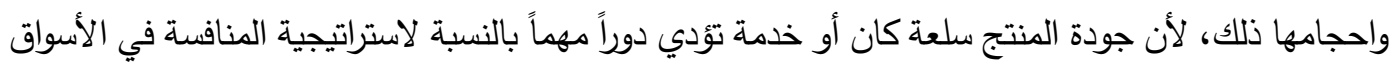
المحلية والاقليمية والعالمية.(Saadallah, 2017:20). والجودة تعني "مجمل الخصائص والميزات الخاصة بالمنتج والقادرة على تلبية حاجات الزبون ورغباته"

.(Das Mulmi, 2014 :5) 
أما بالنسبة للخدمة فقد عرفتها جمعية التسويق الأمركية الخدمات بأنها "النشاطات اوالمنافع التي تقدم

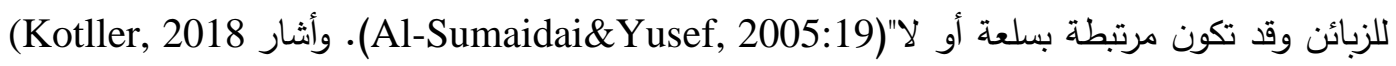

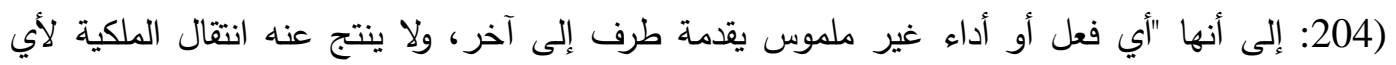

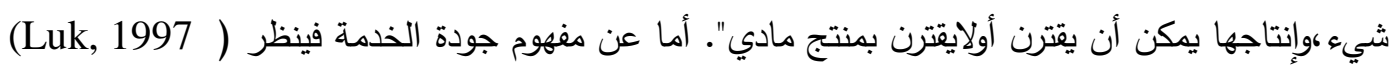

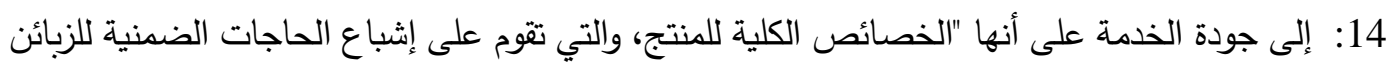

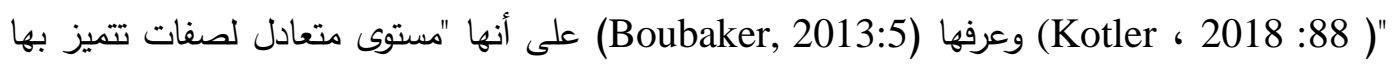

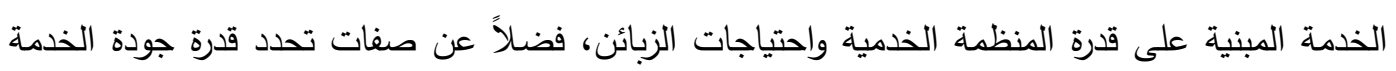
على إثباع حاجاتهم ورغباتهم وهي مسؤولية كل عامل داخل المنظمة". ولجودة الخدمة أهمية كبيرة بالنسبة

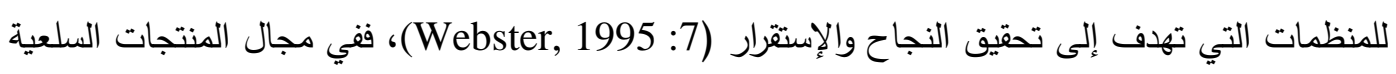
يمكن إستخدام التخطيط في الإنتاج، وتصنيف المنتجات بإنتظار الزبائن، لكن في مجال الخدمات، فإن الزبائن

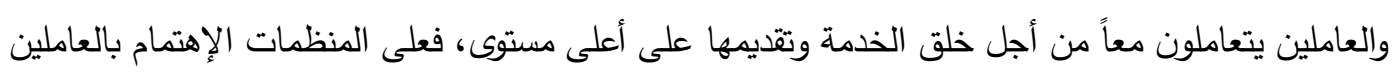
والزبائن معا (AL-Drakah, 2001:151). Diversity_التبوع

إن التتوع في مجال العمل أصبح أحد المبادرات المهمة التي تعتمدها العديد من المنظمات لتحقيق ميزة تنافسية، فهو مصدر قوة ورصيد من الموارد يثري المنظمة بالعديد من العناصر التي يمكن إن تم تعندي

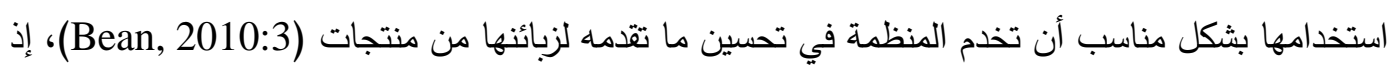

يعد وجود ثقافات متتوعة في المنظمة ميزة تُميز بها المنظمة نفسها عن نظيراتها من المنظمات المنافسة.

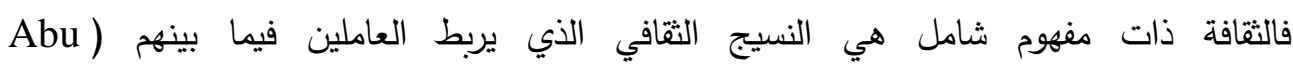

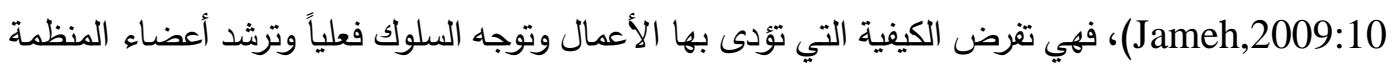
إلى كيف يفهون ويفكرون ويشعرون حيال الأشياء أو الموضوعات (Hussein,2015:59)، كما إنها توفر الإطار أو المقدمة المنطقية التي تبنى عليها القيم (Atheeb\&Saeed,2017:296)، فهي تعبر عن القيم

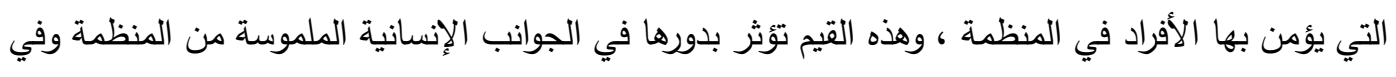

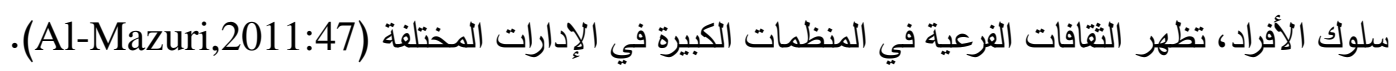

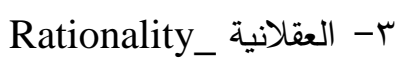

يقصد بالعقلانية أنها" القرار الذي يؤمن الحد الأقصى في تحقيق أهداف التتظيم للمنظمة"

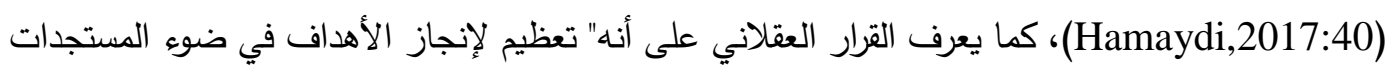

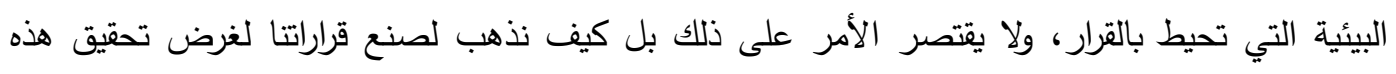
الأهداف" (Atheeb\&Saeed,2017:296)، والقرارات العقلانية" هي ذلك السلوك الذي يستلزم عملية تجميع دئي

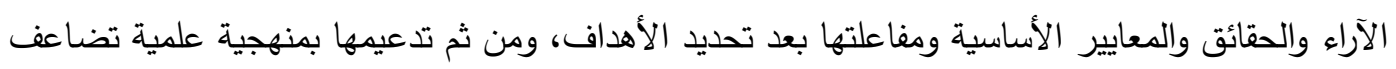
من قيمة النتائج المتوخاة من القرارات المنوي اتخاذها "(AL-Shammari et.al,2013:71). 


\section{الثقافة التسـويقية ودورها في تعزيز الميزة التنافسية .

ع ع العلاقات الداخلية_Internal Relationships

تعبر العلاقات الداخلية عن نظرة المنظمة إلى العاملين فيها، وتقديرها لجهودهم ومراعاة مشاعرهم

وأحاسيسه، وأنماط التفاعل السائد بينهم. وعلى المنظمة أن تتعامل معهم على أنهم جزء مهم في المنظمة

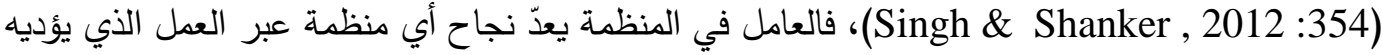
والمقدار الذي يعطيه من جهده وعلمه ومهاراته بوصفه العنصر الوحيد الذي يدير الموارد الأخرى بالمنظمة، الأمر الذي يستلزم الاهتمام به ومتابعة العلاقات الانسانية التي تؤدي إلى رفع روح المعنوية للعاملين، ومن التهن ثمّ إلى الارتقاء بالأداء المنظمي (Abdel-Majeed,2011:2 ). فالمنظمة التي تعامل عامليها بشكل عادل تكون على الأرجح أكثر قدرة على تحقيق الرضا الوظيفي، وكذلك تحقيق رضا الزبون (Sadiq,2011:92)، ومن هنا جاءت أهمية بناء قاعدة لولاء العاملين في المنظمة، لأنها تمكن المنظمات من بناء نوع من علاقات AL-) الثقة مع زبائنها وتعد العلاقات الثخصية القوية واحدة من المحددات المهمة للثقافة التسويقية

.(Mazuri,2011:53

(Innovation) الابتكار

أصبح الابتكار عاملاً مهماً للتميز عن المنافسين، وعلى ذلك فان الابتكار في الخدمات يساعد المنظمات الخدمية المبتكرة في زيادة أرباحها وتحقيق النمو السريع لخدماتها واكتساب حصة سوقية مرتقعة (Hussein,2015:59)، وعرف الابتكار على أنه "تبني المنظمة لأفكار إبداعية لتقدم من خلالها خدمات

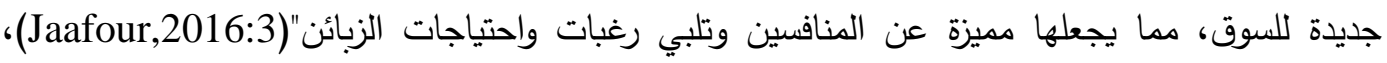
وتظهر أهمية الإبتكار في النقاط الآتية: (Slimani,2007:36) • ينمي ويراكم المهارات الثخصية في التفكير والتفاعل الجماعي من خلال فرق العصف الذهني.

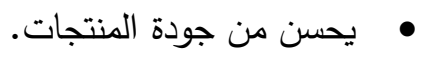
• يزيد من جودة القرارات التي توضع لمعالجة المشكلات على مستوى المنظمة.

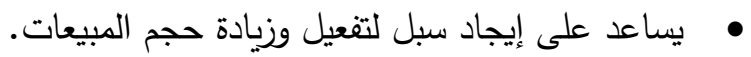
• يساعد على خلق وتعزيز القدرة التتافسية للمنظمة.

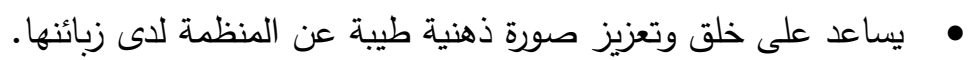
المحور الثاني: مفهوم الميزة التنافسية وأهميتها أولا :مفهوم الميزة التنافسية معومية ارتبط مفهوم الميزة التنافسية بفاعلية المنظمة القادرة على إثباع احتياجات المتعاملين معها من زبائن

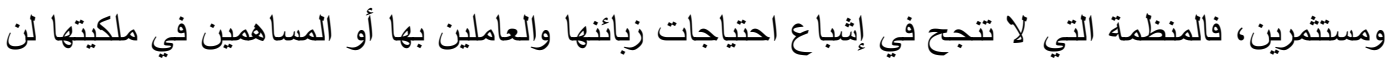
تكون قادرة على تحقيق ميزة تتافسية أمام منافسيها (AL-Raei,2019:19)، وعرفها (Isaac,2013:68) بأنها المقدرة على تفوق المنظمة على المنافسين في بعد أو أكثر من أبعاد الأداء الاستراتيجي، في حين 
أشار (Jurists,2017:23) هي مقدرة المنظمة على تقديم منتج مميز ومبتكر بتكلفة أقل من المنافسين والتركيز باستهداف أسواق وقطاعات سوقية محددة وتلبية حاجاتهم ورغباتهم من خلال أنشطتها المختلفة.

وهناك مصدران للميزة التنافسية هما : (Abbassa,2015:19)

التكلفة الأقل: تؤدي التكلفة دوراً مهماً بوصفها سلاحاً تتافسياً، بالضغط على على التكاليف وأدائها لوظائفها

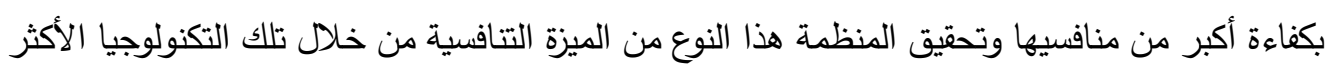
تطورا، أرخص المواد الأولية، الاستغلال الأفضل للطاقات الإنتاجية، كفاءة العمليات التسويقية، فاعلية نظم الإنتاج ونظم الصيانة وكفاءة فعالية عمليات النقل والتخزين. تميز المنتج : التميز في السلعة والخدمة المقدمة سواء على مستوى الجودة ،الإبداع التكنولوجي أو فمائي خدمات ما بعد البيع، وتتمكن المنظمة تحقيق هذا عبر التميز في نوعية وجود المواد الأولية، التميز في

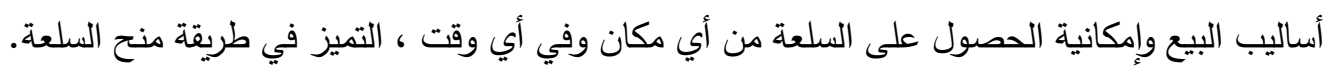
ثانيا:أهمية الميزة التنافسية تكمن أهمية الميزة التتافسية في الآتي: 1. تمثل موشرا إيجابيا للمنظمة بالحصول على أكبر حصة في السوق بما يمكنها من زيادة في حجم الكماتئ

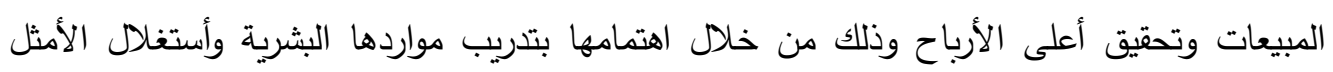

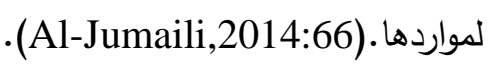
r. تعد الميزة التتافسية معيارا مهما لتحديد المنظمات الناجحة من غيرها، لأن المنظمات الناجحة تتميز

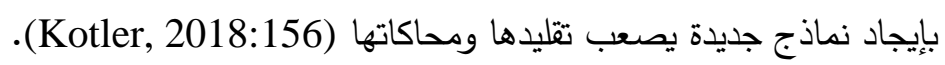
r. خلق قيمة للزبائن وتلبية احتياجاتهم وضمان ولائهم ودعم وتحسين سمعة وصورة المنظمة في أذهانهم(Abubakr,2008:27).

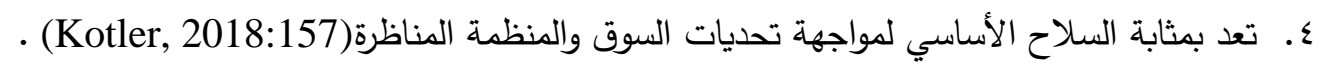

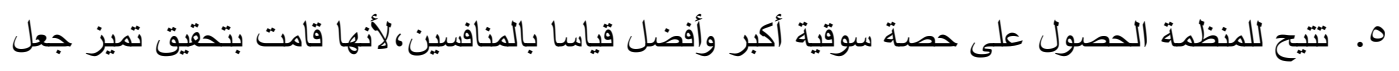
منها الرائدة في السوق المستهدف (Abdel Hamid,2018:53). ثالثا:أهداف الميزة التنافسية تسعى المنظمات من خلال الميزة تتافسية إلى تحقيق الأهداف الآتية ( Ben Ghalboun,2013:39):

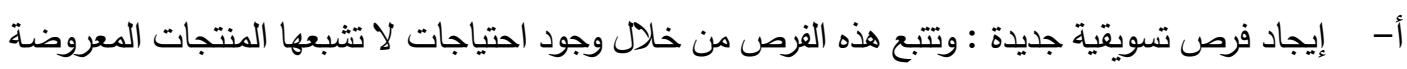

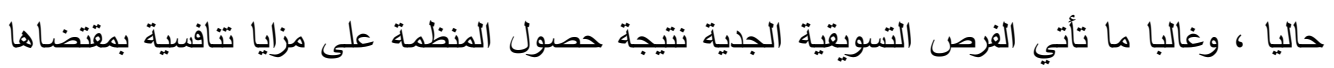

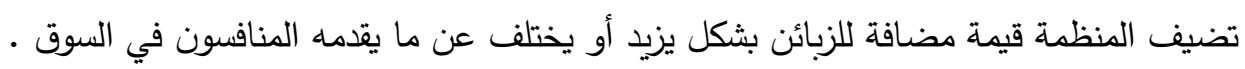

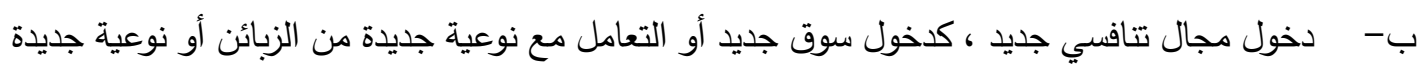

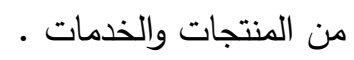
ت- تكوين رؤية مستقبلية جديدة للأهداف التي تريد المنظمة بلوغها وللفرص الكبيرة التي ترغب في اقتتاصها. 
المبحث الثالث: الجانب التطبيقي

المحور الاول: وصف عينة البحث وتثخيصها

أولاً: وصف أفراد العينة

يثير الجدول (1) إلى وصف أفراد عينة البحث وتثخيصهم، إذ تم استخراج التكرارات، والنسب

المئوية، لكل متغير من المتغيرات الوصفية، وتم أخذ معدل الأوساط الحسابية والبالغة (3).

الجدول (1) وصف متفيرات البحث الوصفية وتشخيصها

\begin{tabular}{|c|c|c|c|c|c|c|c|c|c|c|c|c|}
\hline الانعياري & الكسابي & \multicolumn{11}{|c|}{ الجنس } \\
\hline \multirow[t]{4}{*}{$\varepsilon .90}$. & .661 & \multicolumn{4}{|c|}{ المجموع } & \multicolumn{5}{|c|}{ انثى } & \multicolumn{2}{|c|}{ ذكر } \\
\hline & & \multicolumn{2}{|c|}{$\%$} & \multicolumn{2}{|c|}{ العدد } & & $\%$ & \multicolumn{2}{|c|}{ العدد } & & $\%$ & العدد \\
\hline & & \multicolumn{2}{|c|}{100} & \multicolumn{2}{|c|}{$v}$. & & & \multicolumn{3}{|c|}{ ro } & \multirow[t]{2}{*}{$\% \leqslant 0$} & $\leq 0$ \\
\hline & & & & & & & & ن الوظية & & & & \\
\hline \multirow[t]{4}{*}{ rr. 0.} & .441 & \multicolumn{4}{|c|}{ المجموع } & \multicolumn{5}{|c|}{ موظفون فنيون } & \multicolumn{2}{|c|}{ موظفون اداريون } \\
\hline & & \multicolumn{2}{|c|}{$\%$} & \multicolumn{2}{|c|}{ العدد } & & $\%$ & \multicolumn{2}{|c|}{ العدد } & & $\%$ & العدد \\
\hline & & \multicolumn{2}{|c|}{100} & \multicolumn{2}{|c|}{$v$. } & & $\%$ & \multicolumn{3}{|c|}{01} & $65 \%$ & ir \\
\hline & & \multicolumn{10}{|c|}{ المؤهل العلمي } & \\
\hline \multirow[t]{4}{*}{$T r \cdot 0}$. & r.89. & \multicolumn{3}{|c|}{ المجموع } & \multicolumn{3}{|c|}{ ماجستير } & \multicolumn{2}{|c|}{ دبلوم عالي } & & \multicolumn{2}{|c|}{ بكالوريوس } \\
\hline & & $\%$ & \multicolumn{2}{|c|}{ العدد } & \multicolumn{2}{|c|}{$\%$} & العدد & $\%$ & معدد & & $\%$ & العدد \\
\hline & & 100 & \multicolumn{2}{|c|}{$v}$. & \multicolumn{2}{|c|}{$5 \%$} & 7 & $40 \%$ & 1. & & $55 \%$ & $0 \varepsilon$ \\
\hline & & & & & & & & مدة & & & & \\
\hline $0 \wedge 00$. & $.82 r$ & & المج & & & $1-15$ & & & $6-10$ & & & \\
\hline & & $\%$ & العدد & $\%$ & & العدد & & $\%$ & & العدد & $\%$ & العدد \\
\hline & & 100 & v. & 30 & & 1. & & $15 \%$ & & $\varepsilon r$ & $12 \%$ & 11 \\
\hline
\end{tabular}

المصدر: من إعداد الباحثين بالاعتماد على بيانات استمارة الاستبانة ومخرجات التحليل.

ثانياً: وصف متغيرات البحث

يشير الجدول (2) إلى وصف متغيري البحث (الثقافة التسويقية بأبعادها) و (الميزة التتافسية)، إذ تم

استخراج التكرارات، والنسب المئوية، والأوساط الحسابية والانحرافات المعيارية لكل متغير من المتغيرات، وتم

أخذ معدل الأوساط الحسابية والبالغة (r). 
الثقافة التسويقية ودورها في تعزيز الميزة التنافسية ..

خالد ويعقوب

الجدول (2) التوزيعات التكرارية والأوساط الحسابية والانحرافات المعيارية لأبعاد الثقافة التسويقية

\begin{tabular}{|c|c|c|c|c|c|c|c|c|c|c|c|c|}
\hline \multirow{3}{*}{ الانحراف } & \multirow{3}{*}{ الحسطابي } & \multicolumn{10}{|c|}{ قياس الاستجابة } & \multirow{3}{*}{ تسلسل المتغيرات } \\
\hline & & \multicolumn{2}{|c|}{ لا أتفق بشدة } & \multicolumn{2}{|c|}{ لا أتفق } & \multicolumn{2}{|c|}{ محايد } & \multicolumn{2}{|c|}{ أتفق } & \multicolumn{2}{|c|}{ اتفق بشدة } & \\
\hline & & $\%$ & ت & $\%$ & ت & $\%$ & ت & $\%$ & ت & $\%$ & ت & \\
\hline & & & & & & & & & & & & يودة الخدما \\
\hline$\cdot, \vee \leqslant \cdot$ & $r, \Sigma 9 r$ & ----- & --- & --- & --- & $\varepsilon$ & 3 & iv & 12 & $\vee q$ & 55 & X5 \\
\hline$\cdot, \wedge T V$ & $r, r \leq T$ & ----- & --- & r & 2 & r & 2 & r & 16 & VI & 50 & X6 \\
\hline$\cdot, \vee \vee \Lambda$ & $r, 00$. & ---- & --- & V & 5 & V & 5 & rr & 15 & $7 \varepsilon$ & 45 & $\mathbf{X} 7$ \\
\hline$\cdot, \vee \backslash 19$ & Y,OY & ---- & --- & 7 & 4 & 9 & 6 & ro & 18 & 7. & 42 & X8 \\
\hline & & & & & & & & & & & & لعلاقات الدا \\
\hline •, & $r, 09 \varepsilon$ & ---- & --- & --- & --- & 9 & 6 & IV & 12 & Vo & 52 & X9 \\
\hline$\cdot, \vee \vee 90$ & $r, \Gamma \wedge$ & ----- & --- & r & 2 & 7 & 4 & r. & 14 & VI & 50 & X10 \\
\hline$\cdot, \vee \vee q$ & r,Ort & ---- & --- & $\varepsilon$ & 3 & $\varepsilon$ & 3 & $r \varepsilon$ & 17 & $7 V$ & 47 & X11 \\
\hline$\cdot, 71$. & $r, v r q$ & ---- & --- & $\begin{array}{l}-- \\
-\end{array}$ & -- & $\varepsilon$ & 3 & iv & 12 & $\vee q$ & 55 & X12 \\
\hline
\end{tabular}

\begin{tabular}{|c|c|c|c|c|c|c|c|c|c|c|c|c|}
\hline \multicolumn{13}{|r|}{ التنوع } \\
\hline$\cdot, 0 \vee 9$ & $r, v \circ r$ & ---- & --- & 7 & 4 & 9 & 6 & IT & 9 & VT & 51 & X13 \\
\hline$\cdot, 0 \vee 1$ & $r, V)$. & ---- & --- & 7 & 4 & 9 & 6 & rY & 15 & $7 \leq$ & 45 & X14 \\
\hline$\cdot, 0 \wedge 1$ & $r, \Upsilon \wedge l$ & ---- & --- & 1 & 1 & 1 & 1 & $r q$ & 27 & 09 & 41 & X15 \\
\hline$\cdot, 79 \mathrm{~V}$ & $r, 00$. & ---- & --- & 9 & 6 & 7 & 4 & IV & 12 & 79 & 48 & X16 \\
\hline \multicolumn{13}{|r|}{ العقلانية } \\
\hline$\cdot, \vee \vee \wedge$ & $r, r \vee T$ & ---- & --- & r & 2 & 7 & 4 & $r$. & 14 & vo & 52 & X17 \\
\hline$\cdot, \mathrm{V} \wedge \Lambda$ & $r, \varepsilon \leqslant q$ & ----- & --- & V & 5 & V & 5 & $1 \varepsilon$ & 10 & VI & 50 & X18 \\
\hline$\cdot, 791$ & Y,OYI & ---- & --- & 1 & 1 & 1 & 1 & rT & 16 & vo & 52 & X19 \\
\hline$\cdot, \Sigma V \Psi$ & $r, \varepsilon \wedge$. & ---- & --- & 1 & 1 & r & 2 & $1 \varepsilon$ & 10 & Nr & 57 & X20 \\
\hline \multicolumn{13}{|r|}{ الابتكار } \\
\hline$\cdot, \wedge T 1$ & $r, r q)$ & ---- & --- & 1 & 1 & 7 & 4 & IV & 12 & $V_{7}$ & 53 & X21 \\
\hline$\cdot, V \circ V$ & גו, & ----- & --- & $\varepsilon$ & 3 & r & 2 & 17 & 11 & $V V$ & 54 & X22 \\
\hline$\cdot, \times 17$ & 1,070 & ----- & --- & r & 2 & r & 2 & $1 \varepsilon$ & 10 & $\Lambda$. & 56 & $\mathbf{X} 23$ \\
\hline$\cdot, T \vee \leqslant$ & r,0 10 & ----- & --- & r & 2 & 7 & 4 & 11 & 13 & VT & 51 & X24 \\
\hline
\end{tabular}

SPSS VER 24. المصدر: الجدول من إعداد الباحثين في ضوء نتائج برنامج

TANMIYAT AL-RAFIDAIN (P-ISSN: 1609-591X; E-ISSN: 2664-276X) تنمية الرافدين 
يثـير الجدول (2) إلـى التوزيعـات التكراريــة والنسـب المئويــة والأوســاط الحسـابية والانحرافـات

المعيارية للمتغيرات (X5-X24) التي تمثل الأبعاد الفرعية للمتغير المستقل (الثقافة التسويقية)،

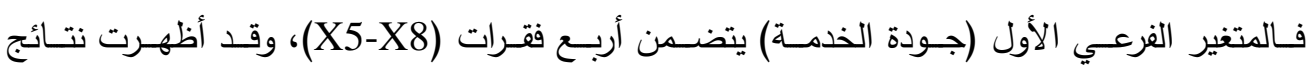
التحليل الآتي:

يتفق ( 96\%) من الأفراد المبحوثين بأنه لاى العاملين في الشركة المبحوثة الوقت الكافي للاستجابة

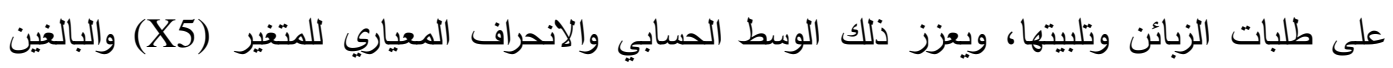

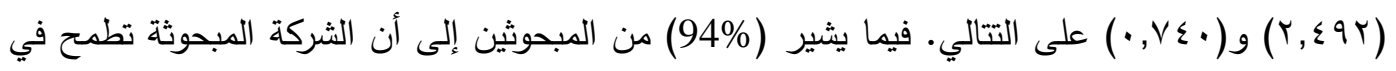

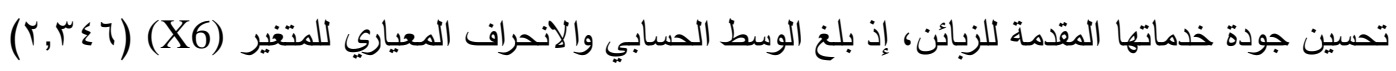

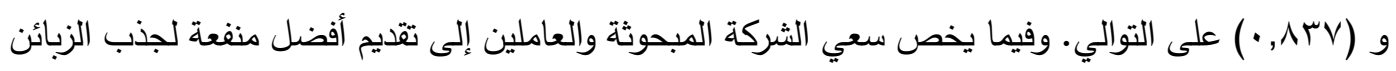

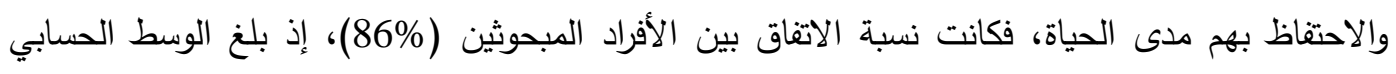

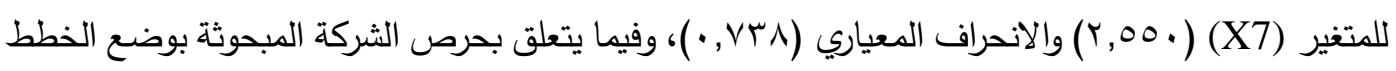
الاستراتيجية التي تولد أفكارا جديدة في تعزيز جودة الخدمة المقدمة، فكانت نسبة الاتفاق بين الأفراد المبحوثين

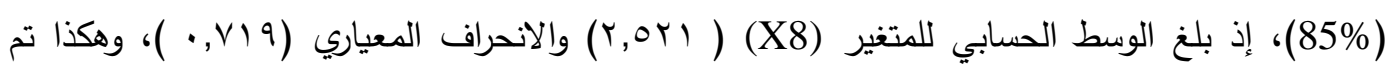

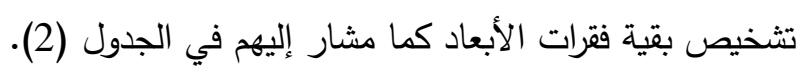

الجدول (3) التوزيعات التكرارية والأوساط الحسابية والانحرافات المعيارية لمتغير الميزة التنافسية فئسية

\begin{tabular}{|c|c|c|c|c|c|c|c|c|c|c|c|c|}
\hline \multirow{3}{*}{ الانحراف } & \multirow{3}{*}{ الحسابي } & \multicolumn{10}{|c|}{ قياس الاستجابة } & \multirow{3}{*}{ تسلسل } \\
\hline & & \multicolumn{2}{|c|}{ لا لأتق } & \multicolumn{2}{|c|}{ لا أتفق } & \multicolumn{2}{|c|}{ محايد } & \multicolumn{2}{|c|}{ أتفق } & \multicolumn{2}{|c|}{ اتفق بثدة } & \\
\hline & & $\%$ & ت & $\%$ & ت & $\%$ & ت & $\%$ & ت & $\%$ & ت & \\
\hline$\cdot, \times \backslash 1$ & $r, T \cdot \lambda$ & - & - & r & r & $\varepsilon$ & r & r) & 10 & vi & 50 & $\mathrm{X} 25$ \\
\hline$\cdot, \vee \vee \vee \neg$ & $r, \varepsilon r \varepsilon$ & - & -- & r & 2 & v & 5 & 19 & 13 & vi & 50 & $\mathrm{X} 26$ \\
\hline$\cdot, V \vee V$ & $r, \varepsilon q 9$ & - & - & 7 & 4 & 9 & 6 & iv & 12 & TV & 47 & $\mathbf{X} 27$ \\
\hline$\cdot, \times 19$ & r,ory & - & - & $\varepsilon$ & 3 & $\varepsilon$ & 3 & iv & 12 & $V \varepsilon$ & 52 & $\mathrm{X} 28$ \\
\hline$\cdot, \vee \vee$. & $r, 0 \cdot V$ & - & - & r & 1 & r & 1 & 17 & 11 & 1) & 57 & $\mathbf{X} 29$ \\
\hline$\cdot, v \leqslant r$ & $r, 01 r$ & - & - & - & - & r & 2 & iv & 12 & $\wedge$. & 56 & $\mathbf{X 3 0}$ \\
\hline$\cdot, 700$ & $r, 0 . V$ & - & - & $\varepsilon$ & 3 & v & 5 & $1 \leqslant$ & 10 & vo & 52 & X31 \\
\hline$\cdot, \vee \vee q$ & $r, \Sigma T r$ & - & - & r & 2 & v & 5 & rr & 16 & TV & 47 & X32 \\
\hline$\cdot, \vee \vee \wedge$ & $r, 00$. & - & - & r & 2 & $\varepsilon$ & 3 & $r$. & 14 & r & 51 & X33 \\
\hline ., VAV & r,rVT & - & - & V & 5 & V & 5 & iv & 12 & 79 & 48 & X34 \\
\hline
\end{tabular}

SPSS VER 24. المصدر: الجدول من إعداد الباحثين في ضوء نتائج برنامج

يثير الجدول (3) إلى التوزيعات التكرارية والنسب المئوية والأوساط الحسابية والانحرافات المعيارية

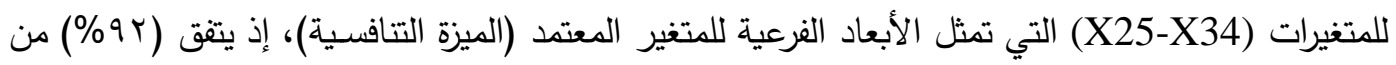


الأفراد المبحوثين، أن الخدمات المقدمة للزبائن تعدّ ذات قيمـة عالية مقارنـة مع الخدمات التي يقدمها

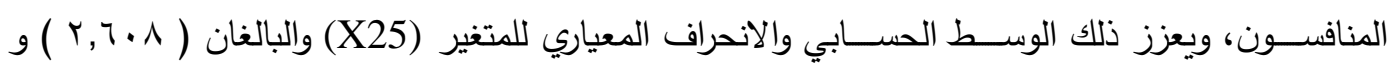

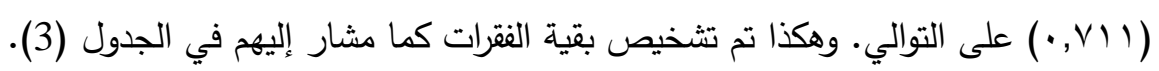
ثالثاً: اختبار فرضيات البحث

لغرض اختبار فرضيات البحث، فإنه يجري اختبار علاقات الارتباط والتأثير لمتغيرات البحث، إذ تم تطبيق بعض الأدوات والاساليب الاحصائية لغرض التعرف على مدى صحة هذه الفرضيات التريات وباستخدام البرمجية الاحصائية 24.

$$
\text { 1- تحليل علاقات الارتباط على المستوى الكلي }
$$

يشير الجدول (4) إلى توضيح علاقات الارتباط البسيط بين المتغير المستقل (الثقافة التسويقية) وبين

المتغير المعتمد (الميزة التنافسية) على نحو عام، وعند مستوى معنوية 0.05 وعلى النحو الآتي:

الجدول (4) علاقات الارتباط البسيط بين متغيري الثقافة التسويقية والميزة التنافسية علية وعنية

\begin{tabular}{|c|c|}
\hline الثقافة التسويقية & المتغير المستقل \\
\hline$* * \wedge .00$ & الميزة التنافسية \\
\hline
\end{tabular}

$* \mathrm{p} \leq 0.05 \quad \mathrm{~N}=70$

SPSS VER.24 المصدر: من إعداد الباحثين بالاعتماد على نتائج البرمجية الاحصائية

يلاحظ من الجدول (4) أن هناك علاقة ارتباط معنوية قوية بين المتغيرين (الثقافة التسويقية والميزة

التتافسية) عند مستوى معنوية (0.05) وهذا إن دلَ إنما يدل على حرص الثركة المبحوثة في الاهتمام بالثقافة

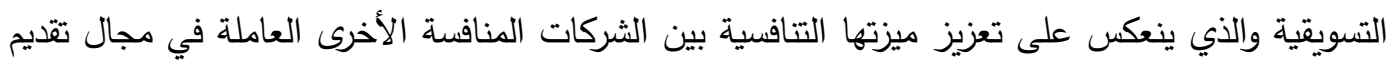
الخدمات الالكترونية ومنها خدمة توفير حزم الانترنت للأشخاص والثركات الأخرى وبجودة عالية. بذلك فئن إنان

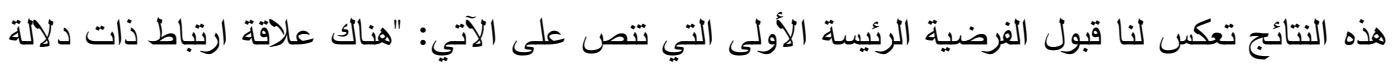

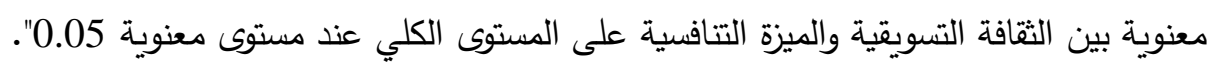
r- تحليل علاقات الارتباط المتعدد على المستوى الجزئي

الجدول(5) نتائج علاقات الارتباط المتعدد بين كل بعد من أبعاد الثقافة التسويقية والميزة التنافسية الجئية

\begin{tabular}{|c|c|c|c|c|c|}
\hline \multicolumn{5}{|c|}{ أبعاد الثقافة التسويقية } & \multirow{2}{*}{ 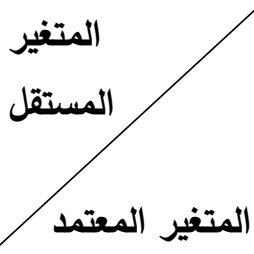 } \\
\hline الابتكار & الثخصبة العلات & العقلانية & التنوع & جودة الخدمة & \\
\hline $0.750 * *$ & $0.886 * *$ & $* * 0.780$ & $0.809 * *$ & $* * 0.885$ & الميزة التنافسية \\
\hline
\end{tabular}

TANMIYAT AL-RAFIDAIN (P-ISSN: 1609-591X; E-ISSN: 2664-276X) تنمية الرافدين 
يوضح الجدول (5) علاقات الارتباط الرتبي بين أبعاد المتغير المستقل (الثقافة التسويقية) والمتغير

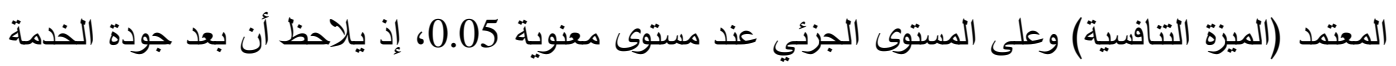
التي تقدمها الثركة المبحوثة للأشخاص والثركات الأخرى، كانت جيدة، وهذا ما يعزز من امكانية تتافسها

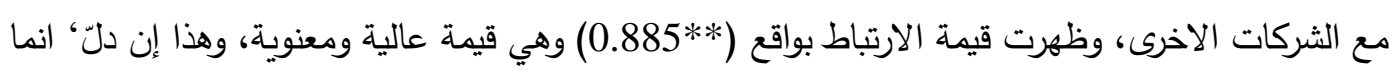

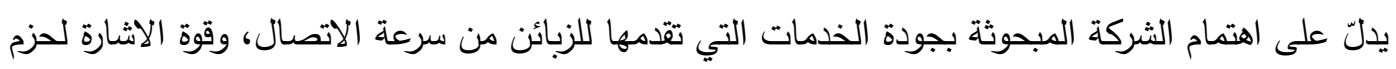

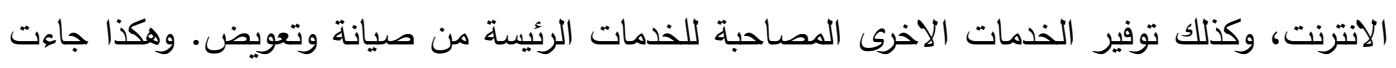
بقية الأبعاد كما مشار لها في الجدول (5) وكلها ذات علاقات ارتباط معنوية، مما يعزز ميزة الثركة التنافسية

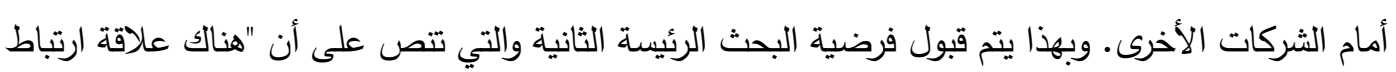

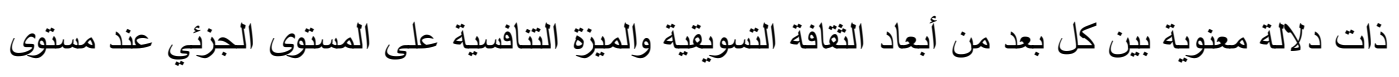

معنوية 0.05. r- تحليل تأثير المتغير المستقل على المتغير المعتمد

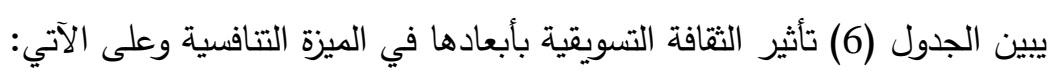
الجدول (6) تأثير الثقافة التسويقية في الميزة التنافسية

\begin{tabular}{|c|c|c|c|c|c|}
\hline \multicolumn{2}{|c|}{$\mathbf{F}$} & \multirow{2}{*}{$\mathbf{R}^{2}$} & \multicolumn{2}{|c|}{ الميزة التنافسية } & \multirow{2}{*}{ المتغير } \\
\hline الجدولية & المحسوبة & & $\beta 1$ & $\beta 0$ & \\
\hline 4.001 & $r \cdot .1 T$ & Arvo. & $\begin{array}{l}\vee q .0 . \\
(16.25)\end{array}$ & $\wedge \Gamma \leq 0$. & الثقافة التسويقية \\
\hline
\end{tabular}

$* \mathrm{p} \leq 0.05$ $\operatorname{df}(1,68)$

$\mathrm{N}=70$

SPSS VER.24 المصدر: من إعداد الباحثين بالاعتماد على نتائج البرمجية الاحصائية

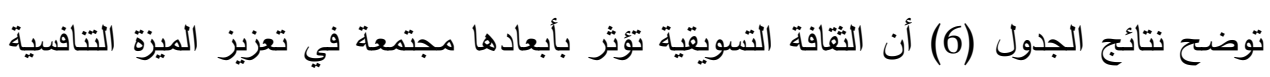
وبمعامل انحدار (0.834) وبدلالة قيمة (T) المحسوبة (16.25) وهي أكبر من قيمتها الجدولية البالغة

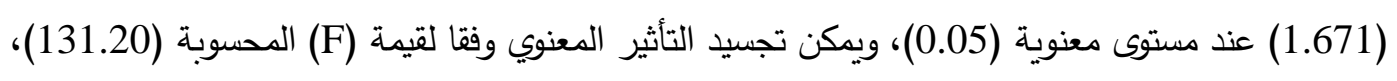
وهي أكبر من قيمتها الجدولية (4.001) وبدرجتي حرية (1.68) (1.05) وند مستوى معنوية (0.05) ومعامل التحديد (R2)

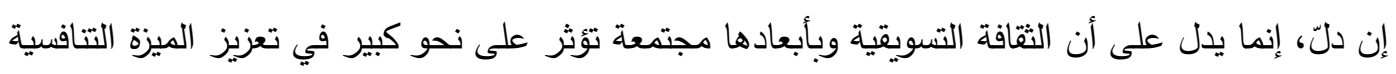

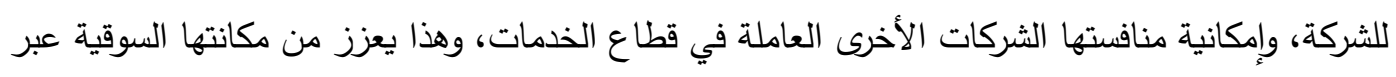

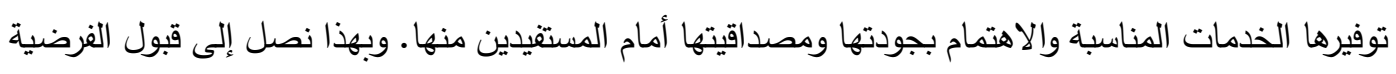
الرئيسة الثالثة للبحث والتي تتص على أن "هناك تأثير معنوي للثقافة التسويقية في الميزة التتافسية عند مستوى

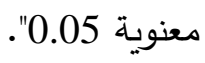




\section{الثقافة التسويقية ودورها في تعزيز الميزة التنافسية ........

$$
\begin{aligned}
& \text { المحور الخامس: الاستنتاجات والمقترحات } \\
& \text { أولاً: الاستنتاجات }
\end{aligned}
$$

ا. إن توافر الثقافة التسويقية بأبعادها لها أهمية في الثركات لاسيما الخدمية كونها في تماس مباشر مع

$$
\text { الزبائن. }
$$

r. تشجيع الثركات على ضرورة الاهتمام بأبعاد الثقافة التسويقية كونها ضرورية لتعزيز الميزة التتافسية،

$$
\text { والتغلب على الثركات المنافسة المقدمة للخدمات لاسيما خدمات الاتصالات والاتترنت. }
$$

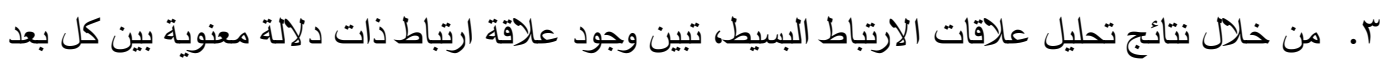

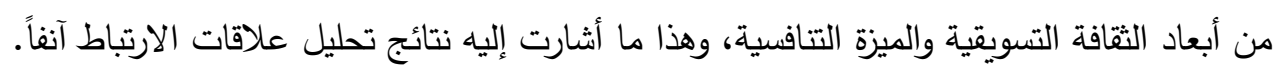

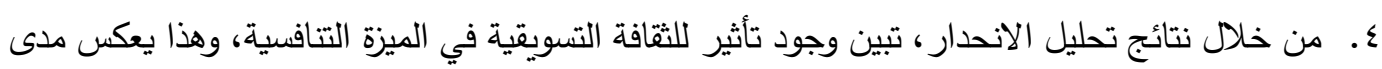

$$
\begin{aligned}
& \text { التأثير لأبعاد الثقافة التسويقية مجتمعة في الميزة التنافسية. } \\
& \text { ثانياً: المقترحات }
\end{aligned}
$$

1- ضرورة الاهتمام بالثقافة التسويقية، وبما تتضمنه أبعادها من متغيرات، كونها تعكس هوية الثركة

$$
\text { ومكانتها بين الشركات المنافسة في السوق. }
$$

r- الاهتمام بجودة الخدمات المقدمة، كونها تتعكس على قوة أدائها الخدمي، وكذلك احتفاظها بزبائنها

$$
\text { الحاليين وجذب زبائن جدد ايضاً. }
$$

r- لكي تحقق الشركات ميزة تتافسية كبيرة على منافسيها، عليها أن تعمل على تلبية احتياجات الزبائن

$$
\text { ورغباتهم عبر تطوير خدماتها المقدمة. }
$$

ـ- - العمل على تقديم الخدمات والعروض المجانية الاضافية من سعات الانترنت للزبائن المشتركين، وهذا

$$
\text { يدل على حرص الثركة بزبائنها وديمومة التواصل معهم. }
$$

\section{References:}

Abbassa, Aisha, (2015), "How to get pleasure related to the wide / Case study of the institution of sugar refinery and the unit of Mostaganem Ram sucre", Master's thesis in commercial sciences, Faculty of Economics, University Abdelhamid Ben Badis-Mostaghanem-, Algeria .

Abdel Hamid, Anas Refaat, (2018), "The Impact of Common Mix Elements, Higher Education/A Field Study on Industrial Plastics Factories in Amman", MBA Thesis, College of Science, Middle East University, Jordan.

Abdel-Majeed, Manal Abdel-Hamid, (2011), "Human Relations and their Impact on Improving Organizational Performance / An exploratory study in Ibn Majid Public Company".

Abu Bakr, Mustafa (2008), "Human Resources: An Introduction to Excellence", First Edition, University House, Egypt.

Abu Jameh, Ibrahim Ahmed Awad (2009), "Culture and Administrative Creativity in the Jordanian Educational Institution", International Conference on Administrative Development: Towards Distinguished Performance in the Governmental Sector, Institute of Public Administration, Riyadh, Saudi Arabia.

TANMIYAT AL-RAFIDAIN (P-ISSN: 1609-591X; E-ISSN: 2664-276X) ننمية الرافدين 


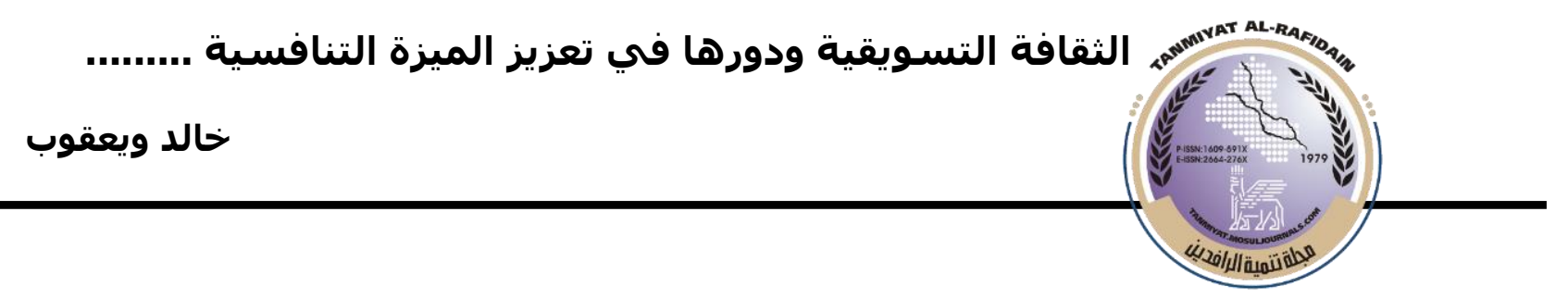

Al-Akidi, Sawsan Ibrahim Rajab, (2013) "Elements of Culture and Dependency as an Introduction to the Requirements of Creativity", unpublished $\mathrm{PhD}$ thesis in Management Philosophy, Departments of Management and Economics, University of Mosul, Iraq.

Al-Drakah, Mamoun (2001), "Total Quality Management", first edition, Dar Safaa for Publishing and Distribution, Jordan.

Al-Jumaili School, Taha Ali Nile, (2014), "The Impact of Human Resources Training by Investigating Small Group in Group / Field Study in the Non-Governmental Circle", an introduction to obtaining a PhD in Business Administration, Faculty of Economics, University of Damascus.

Al-Mazuri, Rajab Zubair Suleiman, (2011), The impact of culture on customer service, a study in government and private departments in Dohuk, Master's thesis, published, College of Administration and Economics, University of Dohuk.

Al-Qadri, Maryam, (2019) "Hajjaj mechanisms in culture and residualism in the traditional industry / case study of the Directorate of Tourism and Handicrafts in AlYaouqi, published master's thesis, Larbi Ben Mhidi-Amqi University, College of Social and Preparatory Sciences.

Al-Raei, Laith Abd al-Latif, (2019), "The Impact of Business Administration at Al-Bayt University.

Al-Shammari, Sadiq Rashid, Al-Azzawi, Muhammad Hassan, and Al-Mashhadani, Ahmad Abdul-Qader, (2013), "The Influence of Some Strategic Factors in the Making and Making of the Voice of Al-Rashidah, Baghdad University Economic College Journal, Volume (2), Issue (34).

Al-Sumaida'i, Mahmoud Jassim, and Yusef, Rudeina Othman (2005), "Strategic Marketing - A Strategic-Quantitative-Analytical Introduction”, First Edition, Dar Al-Manahij for Publishing and Distribution, Jordan.

Atheeb, Amer Fadous and Saeed, Hoda Qassem, (2017), "Building culture is logical and its reflection on the mental image / Journal polls for a sample of managers in the State Company for Vegetable Oil Industry", Economic and Administrative Sciences, Volume (23), Issue (100) .

Bean, Robert , (2010), Managing Cultural Diversity Training Program Resource Manual , Australian Multicultural Foundation, Carlton South, Victoria , Australi. www.harmony.gov.au.

Ben Ghalboun, Fatima Ali, (2013), "The effect of knowledge management on higher education / a field study in hotels in the city of Benghazi", a master's thesis in the Department of Management, Faculty of Economics, University of Benghazi.

Boubaker, Kalthoum, (2013), "The quality of service in the organization and its effects on customer satisfaction", published Master's thesis, Kasdi Merbah University, Algeria.

Das Mulmi , Abhiman, (2014), Quality Concepts , www.scridb.com .

Hamaydi, Dunia, (2017), "Decision-making in the organization between rationality and the culture of actors / a field study of water in the Directorate of Resources_Saeeda, a master's thesis published by Dr. Moulay University.

Hanash, Ahlam and Katebet, Khalaf (2020), "The Reality of Marketing Culture in Algerian Tourism Agencies / A Sample Study of Tourism Agencies in the Wilaya of Algiers," Journal of Economic Research, Volume (15), Issue (1).

Hussein, Intisar Aziz, (2015), the relationship between preparatory vigilance, and its orientation to marketing management, $\mathrm{PhD}$ thesis, Al-Mustansiriya University.

TANMIYAT AL-RAFIDAIN (P-ISSN: 1609-591X; E-ISSN: 2664-276X) تنمية الرافدين 


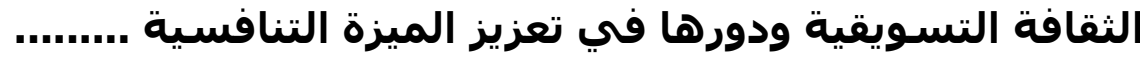 \\ خالد ويعقوب}

Jaafour, Khadija, (2016), "Statistics in Statistics in Statistical Numbers in the Statistical Performance of the Situation / Case Study of the Elf Hotel in Ouargla State", Master Thesis at Kasadi University, Ouargla, Faculty of Economic Sciences, Commercial Sciences and Management Sciences, Algeria.

Jurists, Zaid Nayel, (2017), "The Impact of Human Resource Management Activities on Educational Knowledge in the Knowledge Group in the Jordanian Communications Society", Master Thesis in Human Resources Management, College of Business Administration, Amman Arab University.

Kotler, Philip, (2018) , Marketing Management, Analysis, Planning, Implementation and Control , 9th Ed., Prentic-Hall, New Delhi.

Luk, Sherriff T.K. , (1997), An examination of the role of marketing culture in service quality, International Journal of Contemporary Hospitality Management, Vo. 9, No.1.

Saadallah, Nour Muhyiddin, (2017), "Quality of Services and their Impact on Achieving Quality of Satisfaction / Field Study: The Sudanese Islamic Bank and the Bank of Savings and Social Development", Master Thesis in Postgraduate Studies, Republic of Sudan.

Sadiq, Derman Suleiman, (2011), "Measuring the Area of Culture in Banking Relations: An Exploratory Study of the Opinions of a Sample of a Journal of Private Commercial Banks in the Governorates of the Kurdistan Region of Iraq", Karbala Scientific University, Vol (9), No. (2).

Singh, Vidit \& Shanker, Ravi , (2012) , Marketing Culture: Gap Analysis of select Indian Commercial Banks , IRACST- International Journal of Research in Management \& Technology (IJRMT), Vol. 2 , ISSN: 2249-9563, No.3, June .

Slimani, Mohamed, (2007), "Marketing innovation and its impact on improving the performance of the institution / Case study of the Al-Hodna Dairy Foundation", a master's thesis submitted to the Department of Facilitation and Marketing Sciences / Messila University, Algeria

Webster, Cynthia , (1995 ), Marketing Culture and Marketing effectiveness in Service Firms , The Journal of Services Marketing, Vol.9, No. 2.

yildirim,sada,Acaray,Ali,Aydin,kenan(2017), "Exploring the impact of marketing culture on job satisfaction",World Journal of Entrepreneurship,managamant and Sustainable Development,vol.13,NO

TANMIYAT AL-RAFIDAIN (P-ISSN: 1609-591X; E-ISSN: 2664-276X) تنمية الرافدين 